\title{
A Case Report on Effectiveness of Early Physiotherapy Rehabilitation Approach for Colles' Fracture
}

\author{
Heena Pathan ${ }^{1}$, Anushree Pawar ${ }^{1}$, Ruchita Rao ${ }^{1}$, Pratik Phansopkar ${ }^{2}$ and Obaid Noman ${ }^{3}$ \\ ${ }^{1}$ Final year B.PT, Ravi Nair Physiotherapy College, Datta Meghe \\ Institute of Medical Sciences (DU) Wardha, Maharashtra, India \\ ${ }^{2}$ Department of Musculoskeletal Sciences, Ravi Nair Physiotherapy College, \\ Datta Meghe Institute of Medical Sciences (DU) Wardha, \\ ${ }^{3}$ Department of Pathology, Jawaharlal Nehru Medical College, Datta Meghe \\ Institute of Medical Sciences, Sawangi Meghe, Wardha \\ Corresponding author email: drpratik77@gmail.com
}

\section{ABSTRACT}

Colles' fracture specifically is defined as metaphyseal injury of cortico-cancellous junction of distal radius. The incidence has been shown to follow bimodal distribution; in general those most affected are in first and seventh decade of life. Distal radius fracture have high incidence among the aging population. Comminuted fracture of distal end of the radius are caused by severe trauma and presents as shear and impacted fracture of articular surface. The type of fracture and localization, degree of displacement, patient's age and magnitude of soft tissue injury are the factors to be considered for treatment options. A 19 year old female reported to casualty with pain, swelling, tenderness and deformity over right wrist. Patient had history of fall from stairs 2 months back and sustained trauma to her to her right wrist. She was unable to performher daily activities with right hand. X-ray findings confirmed displaced comminuted fracture of distal end of right radius Medicinal and therapeutic intervention was given. Therapeutic intervention included thermotherapy, range of motion exercises, joint mobilization and progressive resistive exercise. Functional improvement was observed after 12 weeks of physiotherapy. Early start of physiotherapy after fixation of fracture can improve forearm functioning and quality of life.

KEY WORDS: COLLE'S FRACTURE,DISTAL END RADIUS, OPEN REDUCTION, INTERNAL FIXATION, PHYSIOTHERAPY REHABILITATION.

\section{INTRODUCTION}

For high quality life of patient, forearm functioning is very important. Colles' described fractures of distal extremity of radius in 1814 (Belloti et al., 2017). Colles' fracture is defined as "metaphyseal injury of corticocancellous junction (within 2-3 cm of articular surface)

Biosc Biotech Res Comm P-ISSN: 0974-6455 E-ISSN: 2321-4007

\section{crossef}

Identifiers and Pagination

Year: 2021 Vol: 14 No (6) Special Issue

Pages: 95-99

This is an open access article under Creative

Commons License Attribn 4.0 Intl (CC-BY). DOI: $h t t p: / / d x$.doi.org/10.21786/bbrc/14.6.22 of distal radius with characteristic dorsal tilt, dorsal shift, radial tilt, radial shift, supination and impaction"( Meena et al., 2017).The incidence has been shown to follow bimodal distribution; in general those most affected are in first and seventh decade of life (Tosti et al., 2011). The incidence of distal radius fracture is higher among the olderresulting in poor functional outcomes and impairments (Ikpeze et al. 2016). Strong trauma is the usual cause of comminuted fracture of distal end of the radius and there may be fracture of articular surface of distal radius with displacement of fragments (Mader et al., 2006). The type of fracture and localization, degree of displacement, patient's age and magnitude of soft tissue injury are the important factors to determine treatment

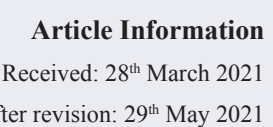
ccepted after revision: $29^{\text {th }}$ May 2021 
options. Careful evaluation of distal radioulnar joint (DRUJ) is also important (Gurselsaka et al., 2013).

The mechanism of injury is normally a fall on outstretched hand with wrist in dorsiflexion. The form and severity depends upon position of wrist at the moment hitting the ground. There will be sudden pain with movement, bruising, swelling, tenderness on palpation of distal end radius. A displaced fracture will typically result in wrist disfigurement (dinner fork deformity) (Kvernmo et al., 2015). The X-ray of forearm and wrist is useful for diagnosis. Treatment modalities of fracture include cast immobilization or surgical treatment like internal or external fixation, pinning and bone substitute (Dudhamal et al., 2012).

To ensure an efficient and safe post-operative rehabilitation with protection of soft tissue during the operation, stable fracture fixation is advised (MericUgurlar et al., 2017). The rehabilitation aims at rapid functional restorationand prevention of chronic disability (Charls et al., 2001). A Colles'fracture usually heals completely in 8 weeks. X-ray can be taken time to time to assess the healing. After removal of the cast, the affected sides wrist, fingers, hand, elbow and shoulder are usually stiff for several weeks and needs exercise and physical therapy (Dudhamal et al., 2012). This is a case of young women with unstable, displaced distal radial fracture which was treated with open reduction internal fixation using locked volar plate. Initiation of early physiotherapy intervention helped to improve quality of life and forearm functioning.

Patient Information: A 19 year old female who live in Wardha town is a student of third year. Hand dominance right, experience pain, swelling, tenderness and deformity since trauma over right wrist which is gradually progressive. Patient presents with history of fall from stairs 2 months back and sustained trauma to her to her right wrist. She was brought to casualty by her relatives. After initial investigations in Wardha she was diagnosed with undisplaced comminuted fracture of distal end radius right side her parents were advised to take her to AVBRH Sawangi (M) Wardha by the physician. She came to AVBRH Orthopedic department on 10 January 2019 with compliant of severe pain, swelling and deformity since trauma.There is history of hair-line fracture of neck humerus of left shoulder and green stick fracture of distal inch radius right wrist.

Patient was managed conservatively both times. Consultant orthopedic surgeon advised X-ray and laboratory test. X-ray of right forearm interpreted displaced comminuted facture of distal end radius.For this she was operated on 14 January 2019. Post-operation patient was treated with analgesics and below elbow slab was given. Active finger movement, limb elevation on pillow was advised. After 2 days she was discharge and was called for follow-up after 14 days. Patient came for follow-up on 29 Jan 2019, sutures were removed and Slab was given for 1 month.
After 1 month on 28 Feb 2019, slab was removed and check radiograph was done. Crepe bandage was given. Later physiotherapy consultation accompanied 2 months later post-surgery that is on 1 March 2019. Post-operatively patient had chief complaints of pain in right wrist which patient describe as dull aching type with intensity of 6/10 at rest and 8/10 on activity on NPRS which aggravated on activities, swelling, stiffness, also unable to perform range of motion (ROM) at wrist due to prolong immobilization in plaster slab and difficulty in performing activities of daily living such as self-hygiene.

Clinical Findings: After taking informed consent from patient, she was examined in sitting position with both shoulders at level. On physical examination, vital signs including temperature were normal, pulse rate 76 beats/ min, RR- 24 breaths/min, and BP-120/80 mmHg. On inspection patient kept right shoulder adducted and elbow flexed to approx 900, forearm mid pronated, wrist in neutral and interphalengeal joints in mid flexion position. Presence of scar was over anterior aspect distal forearm with visible swelling at wrist. On palpation local temperature was not raise, diffuse tenderness grade 2 and scar length was $9 \mathrm{~cm}$. Neurological assessment was normal. Myotome assessment, it was limited due to injury however grossly impaired from C5, C6 and C7 in right upper extremity and deep tendon reflexes were found intact. X-ray and clinical photograph are shown in figure below.

\section{Clinical Photograph:}

Therapeutic Intervention: Patient was given physiotherapy for 12 weeks (5 days a week) which included sessions on patient's education and thermotherapy. Also range of motion exercises, joint mobilization and progressive resistive exercise were conducted.

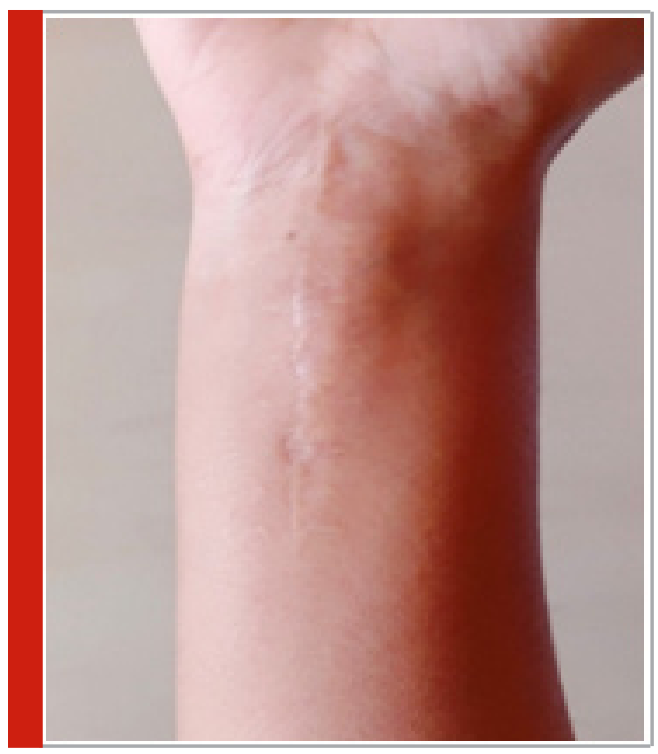

Radiological Images 


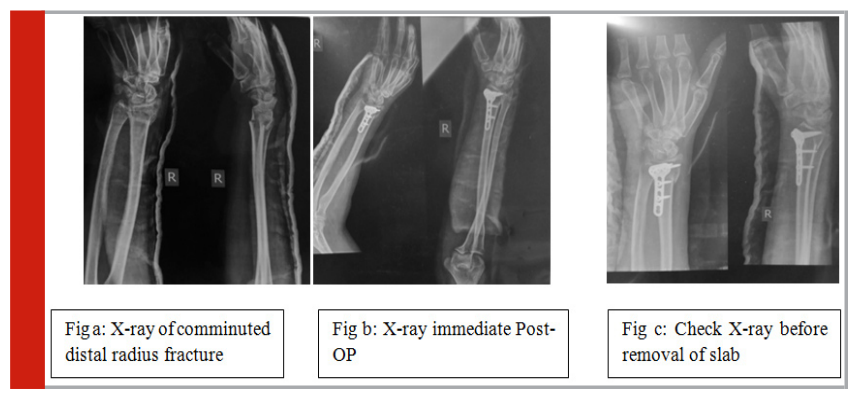

Description

During immobilization: Full range of strong forceful active finger movements were followed. Active Range of Motion exercises to digits, thumb, elbow and shoulder were given to prevent stiffness.Wrist movement, supination and pronation were not encouraged. Dependent edema was treated by limb elevation on pillow above elbow and elbow above the shoulder. Care of plaster slab and checking it to see that it is not hampering the full range of MCP joints of finger and thumb. Intermittent use of sling with elbow in at least 700 of flexion. It should be check for slackness and padding under neck.

\section{On removing the plaster:}

\section{Week 1}

Thermotherapy for 10-15 minutes to induce relaxation, improve circulation and reduce pain, stiffness around the joint and puts joint in an ideal position for exercise.Scar mobilization using deep friction massage by applying pressure of varying intensities with ball of thumb and fingers performed for 30 seconds to $1 \mathrm{~min}$.Exercises to improve Flexion - extension includes Wrist mobilization is initiated Stabilizing the forearm just above the wrist joint and small range of relaxed passive movement flexion-extension in midprone position is performed.

\begin{tabular}{|c|c|}
\hline \multicolumn{2}{|l|}{ Timeline } \\
\hline Diagnosed with undisplaced comminuted facture & $8 / 1 / 2019$ \\
\hline Admitted at Hospital(diagnosed with displaced fracture) & $10 / 1 / 2019$ \\
\hline Operated (open reduction internal fixation) & $14 / 1 / 2019$ \\
\hline Discharge & $16 / 1 / 2019$ \\
\hline Follow up 1 (sutures removed \&t plaster slab re-applied) & $29 / 1 / 2019$ \\
\hline Follow up 2 (plaster slab removed) & $28 / 2 / 2019$ \\
\hline Physiotherapy Rehabilitation & $1 / 3 / 2019$ \\
\hline
\end{tabular}

\begin{tabular}{|c|c|c|c|c|c|}
\hline \multirow[b]{2}{*}{ Joint } & \multirow[b]{2}{*}{ Movements } & \multicolumn{2}{|c|}{ Pre treatment } & \multicolumn{2}{|c|}{ Post treatment } \\
\hline & & Active & Passive & Active & Passive \\
\hline \multirow[t]{2}{*}{ Elbow } & Flexion & $120^{\circ}$ & $125^{0}$ & $140^{\circ}$ & $140^{\circ}$ \\
\hline & Extension & $0^{0}$ & $0^{0}$ & $0^{0}$ & $0^{0}$ \\
\hline \multirow[t]{2}{*}{ Forearm } & Pronation & $40^{\circ}$ & $45^{0}$ & $87^{0}$ & $90^{\circ}$ \\
\hline & Supination & $30^{\circ}$ & $40^{\circ}$ & $85^{\circ}$ & $90^{\circ}$ \\
\hline \multirow[t]{4}{*}{ Wrist } & Flexion & $35^{0}$ & $40^{\circ}$ & $75^{0}$ & $75^{0}$ \\
\hline & Extension & $35^{0}$ & $42^{0}$ & $70^{\circ}$ & $72^{0}$ \\
\hline & Radial deviation & $10^{\circ}$ & $12^{0}$ & $20^{\circ}$ & $20^{\circ}$ \\
\hline & Ulnar deviation & 15 & $20^{\circ}$ & $30^{\circ}$ & $35^{0}$ \\
\hline
\end{tabular}

Table 2. Manual Muscle Testing Pre and Post Treatment

\begin{tabular}{|c|c|c|c|}
\hline & & Pre treatment & Post treatment \\
\hline \multirow[t]{2}{*}{ Elbow } & Flexors & 4 & 5 \\
\hline & Extensor & NT & NT \\
\hline \multirow[t]{2}{*}{ Wrist } & Flexors & $3-$ & 4 \\
\hline & Extensors & $3-$ & 4 \\
\hline
\end{tabular}

\section{Week 2-4}

Thermotherapy and range of motion exercises are continued. Graded joint mobilization was started with II-III (Maitland) dose at 3 bouts of 30 seconds interval, followed by cryotherapy for 7-8 minutes. Alternately Indian salutation and Reverse salutation were done. As the range improves isometrics, isotonic self-resistive exercises and strengthening using therapy balls to improve grip strength were done.

\section{Week 5-8}

Thermotherapy and range of motion exercises are continued. Graded joint mobilization progressed to IIIIV (Maitland) dose at 3 bouts of 30 seconds interval, followed by cryotherapy for 7-8 minutes. Muscle Energy Technique was started at end range of motion. Patient was asked to initiate flexion, extension, supination and pronation.Reciprocal inhibition followed by post isometric relaxation (3-5 repetition) was done. 


\section{Week 8-12}

Static stretching to elbow and wrist along with active range of motion exercises were done. Functional task oriented exercises such as turning keys, door knobs, scooping beans and putting in box were started for reducing difficulty in daily living. Functional use of whole upper extremity especially forearm wrist and hand was encouraged and progressed right from initial stage.

Follow up and outcome: Table shows initial and final evaluation of range of motion and strength evaluation. After 12 weeks, improvement was reported. Remarkable decrease in pain on NPRS from $6 / 10$ to $1 / 10$ at rest and $8 / 10$ to $2 / 10$ during activity was seen.

PSFS (Patient Specific Functional Scale)

Patient capacity increased in activities like grooming, eating, and writing .

Pre score $-1 / 10$

Post score $-6 / 10$

NPRS (Numerical Pain Rating Scale)

Pre score $-8 / 10$

Post score - 2/10.

\section{DISCUSSION}

In this case, patient reported with complain of pain and stiffness along with reduced strength, decreased range of motion and difficulty in doing activities of daily living. A plan of care was made after careful clinical evaluation. Intervention included thermotherapy, range of motion exercises, stretching, graded joint mobilization and muscle energy techniques. Starting early physiotherapy post cast removal regularly shows significant increase in wrist extension and grip strength. Active range of motion exercises are beneficial to facilitate the pumping action of hand muscles and to reduce the swelling and oedema. Heating benefits in both active range of motion gain and persistent ROM gain (Nakano et al., 2012). Initial therapy of ice, paraffin wax bath application and gentle range of motion mobilization helps in improvement of both range of motion and grip strength. ROM exercises were initially initiated to advance passively towards active assisted exercises and then free exercises. Graded joint mobilization (Maitland) was given in grades II-III and progressed to III-IV, 3 bouts at interval of 30 second. After mobilization an Ice pack for 7-10 minutes were added.

Application of Ice pack helps to reduce inflammation result from tissue tension of joint mobilization, reduces any discomfort after treatment-induce micro trauma, reduces any secondary ischemic injury and it improved plastic tissue elongation (Draper et al., 2010). Manipulative management show significant increase in range of motion. Muscle energy technique for biceps and triceps was integrated, from reciprocal inhibition to post isometric relaxation (Sakina et al., 2017). Mundada et al. (2017) reported a case of Type-I Monteggia with ipsilateral fracture of distal radius epiphyseal injury 14.
Similar articles are reported in GBD studies (James et al., 2017; Spencer et al., 2020; Murray et al., 2020; Murray et al., 2017). Studies on different types of fracture were also reported by Dhankar and Bele (2019), Reddy and Dhaniwala (2019). Related articles and cases were reported by Bawiskar et al. (2020) , Phansopkar et al. (2020), Reddy et al. (2020) and Saoji et al.(2020).

\section{CONCLUSION}

The above study concludes that definitive surgical approach and early physiotherapy rehabilitation lead to enhancement in functional goals of patient which stands a major understanding towards a successful recovery.

\section{Conflict of interest: None}

\section{Funding support: None}

Patient consent: Proper consent was taken from the patient for writing case report.

\section{List of abbreviation}

DRUJ - Distal Radio-ulnar Joint

ORIF - Open Reduction Internal Fixation

ROM - Range Of Motion

MET - Muscle Energy Technique

NPRS - Numerical Pain Rating Scale

PSFS - Patient Specific Outcome Measure

\section{REFERANCES}

Bawiskar, D.P., Bais, A.S., Naqvi, W.M. and Sahu, A., 2020. Physiotherapy Approach towards a Typical Case of Injection Induced Radial Nerve Palsy Presenting as Wrist Drop. Journal of Evolution of Medical and Dental Sciences, 9(22), pp.1722-1725.

Belloti, J.C., Santos, J.B.G.D., Atallah, Á.N., Albertoni, W.M. and Faloppa, F., 2007. Fractures of the distal radius (Colles' fracture). Sao Paulo Medical Journal, 125(3), pp.132-138.

Bhinderwala, S., Wani, S.K. 2017. Case study of Radial Head Displacement Rehablitation. 1(1), pp.37-41.

Charls, A., Goldfarb, Yuming, Y., Louis, A. Gilula. 2001. Wrist fracture:Whattheclinician wants to know, 219, pp.11-28.

Dhankar, S. and Bele, A., 2019. A case of fracture shaft femur in a patient with transtibial amputation. Journal of Datta Meghe Institute of Medical Sciences University, 14(4), p.394.

Draper, D.0., 2010. Ultrasound and joint mobilizations for achieving normal wrist range of motion after injury or surgery: a case series. Journal of athletic training, 45(5), pp.486-491.

Dudhamal, T.S., Mahanta, V.D. and Gupta, S.K., 2012. Efficacy of Lakshadi Plaster and Laksha Guggulu in the Management of Bhagna (Stable Colle's Fracture) Case Report. International Journal of Ayurvedic Medicine, 3(2), pp.124-129. 
Gurselsaka, Needet, S., Tuhan, K. 2013. Treatment of isolated diaphyseal fracture of radius with intramedullary nail in adults.

Hebe Desiree, K., YngurKrukhaug. 2015. Treatment of distal radius fractures.133, pp.405-410.

James, S.L., Castle, C.D., Dingels, Z.V., Fox, J.T., Hamilton, E.B., Liu, Z., Roberts, N.L., Sylte, D.O., Bertolacci, G.J., Cunningham, M. and Henry, N.J., 2020. Estimating global injuries morbidity and mortality: methods and data used in the Global Burden of Disease 2017 study. Injury Prevention, 26(Supp 1), pp.i125-i153.

Latchoumi, T.P., Ezhilarasi, T.P. and Balamurugan, K., 2019. Bio-inspired weighed quantum particle swarm optimization and smooth support vector machine ensembles for identification of abnormalities in medical data. SN Applied Sciences, 1(10), pp.1-10.

Mader, K., Pennig, D. 2006.The treatment of severely comminutedintrarticular fracture of distal radius.1,pp.217.

Meena, S., Sharma, P., Sambharia, A.K. and Dawar, A., 2014. Fractures of distal radius: an overview. Journal of family medicine and primary care, 3(4), p.325.

Mundada, G., Khan, S.M., Singhania, S.K., Gupta, V., Singh, P.K. and Khan, S., 2017. Type-I monteggia with ipsilateral fracture of distal radius epiphyseal injury: A rare case report. Annals of African medicine, 16(1), p.30.

Murray, C.J., Abbafati, C., Abbas, K.M., Abbasi, M., Abbasi-Kangevari, M., Abd-Allah, F., Abdollahi, M., Abedi, P., Abedi, A., Abolhassani, H. and Aboyans, V., 2020. Five insights from the global burden of disease study 2019. The Lancet, 396(10258), pp.1135-1159.

Murray, C.J., Aravkin, A.Y., Zheng, P., Abbafati, C., Abbas, K.M., Abbasi-Kangevari, M., Abd-Allah, F., Abdelalim, A., Abdollahi, M., Abdollahpour, I. and Abegaz, K.H., 2020. Global burden of 87 risk factors in 204 countries and territories, 1990-2019: a systematic analysis for the Global Burden of Disease Study 2019. The Lancet, 396(10258), pp.1223-1249.

Nakano, J., Yamabayashi, C., Scott, A. and Reid, W.D., 2012. The effect of heat applied with stretch to increase range of motion: a systematic review. Physical Therapy in Sport, 13(3), pp.180-188.

Phansopkar, P., Athawale, V., Birelliwar, A., Naqvi, W. and Kamble, S., 2020. Post-operative rehabilitation in a traumatic rare radial nerve palsy managed with tendon transfers: a case report. The Pan African Medical Journal, 36.

Reddy, S. and Dhaniwala, N., 2019. Diaphyseal fractures in pediatric age group in rural area: A demographic study. Journal of Datta Meghe Institute of Medical Sciences University, 14(3), p.189.

Reddy, S.M. and Dhaniwala, N.S., 2020. Outcome of Surgically Managed Diaphyseal Fractures in Children-A Prospective Study. JOURNAL OF EVOLUTION OF MEDICAL AND DENTAL SCIENCES-JEMDS, 9, pp.39397.

Saoji, K., Mohit, D., Gajanan, P., Aditya, K., Amit, S. 2020. Infected Non Union in an Operated Compound Fracture of Shaft of Humerus: A Case Report. MEDICAL SCIENCE, 24 (105), pp. 3215-3221.

Spencer, L., Chris, D., Zachary, V., Jack, T., Erin, B., Zichen, L., Nicholas, L., Roberts, S., Dillon, O., Nathaniel, J. and Kate, E., 2019. Global injury morbidity and mortality from 1990 to 2017: results from the Global Burden of Disease Study 2017.

TochukwuC.Ikpeze, Heather C.Smith, Daniel J.Lee. 2016. Distal radius fracture outcome and rehabilitation,7(4), pp.202-205.

Tosti, R., Foroohar, A., Park, M.J., Steinberg, D.R. 2011. Distal radius fracture,62, pp.443-457.

Ugurlar, M., Kabakas, F., Sonmez, M.M., Erturer, R.E., Mersa, B. and Ozcelik, I.B., 2017. The plate fixation in the treatment of complex forearm open fractures. Hand and Microsurgery, 6(1), pp.1-8.

Vos, T., Lim, S.S., Abbafati, C., Abbas, K.M., Abbasi, M., Abbasifard, M., Abbasi-Kangevari, M., Abbastabar, H., Abd-Allah, F., Abdelalim, A. and Abdollahi, M., 2020. Global burden of 369 diseases and injuries in 204 countries and territories, 1990-2019: a systematic analysis for the Global Burden of Disease Study 2019. The Lancet, 396(10258), pp.1204-1222. 